\title{
Tissue Thiol Concentration in High-Grade Gliomas: Is There any Association Between IDH1 Mutation Presence and Tumoral Cellular Antioxidant Defense?
}

\author{
Sevket EVRAN ${ }^{1}$, Ahmet KAYHAN ${ }^{1}$, Oguz BARAN², Serdar CEVIK ${ }^{3}$, Salim KATAR ${ }^{4}$, Mustafa KAYA ${ }^{5}$, \\ Derya SONMEZ ${ }^{6}$, Huriye SERIN ${ }^{6}$, Hakan HANIMOGLU ${ }^{7}$, Mehmet Yasar KAYNAR ${ }^{8}$ \\ ${ }^{1}$ Haseki Research and Training Hospital, Neurosurgery Clinic, Istanbul, Turkey \\ ${ }^{2}$ Koc University Hospital, Department of Neurosurgery, Istanbul, Turkey \\ ${ }^{3}$ Gelisim University, School of Health Sciences, Istanbul, Turkey \\ ${ }^{4}$ Balikesir University, Medical Faculty, Department of Neurosurgery, Balikesir, Turkey \\ ${ }^{5}$ Sakarya University Education and Research Hospital, Department of Neurosurgery, Sakarya, Turkey \\ ${ }^{6}$ Istanbul Research and Training Hospital, Clinical Biochemistry Laboratory, Istanbul, Turkey \\ ${ }^{7}$ Biruni University, Medical Faculty, Department of Neurosurgery, Istanbul, Turkey \\ ${ }^{8}$ Istanbul University-Cerrahpasa, Medical Faculty, Department of Neurosurgery, Istanbul, Turkey
}

Corresponding author: Sevket EVRAN sevketevran@hotmail.com

\section{ABSTRACT}

AIM: To assess and compare the antioxidant capacities of high-grade gliomas (HGG) according to their grades and the presence of isocitrate dehydrogenase 1 (IDH1) mutation using tissue thiol level measurement.

MATERIAL and METHODS: Tissue thiol concentrations were measured in $41 \mathrm{HGG}$ samples and 21 healthy brain tissues obtained from autopsy procedures, which were performed within the first 4 hours of death. All samples were stored at $-80^{\circ} \mathrm{C}$, and a thiol quantification kit was used in evaluating tissue thiol levels. The Number Cruncher Statistical System was used for statistical analyses to detect the differences between the control group and the HGG group, which was also divided into subgroups according to their grade and IDH1 mutation presence.

RESULTS: The tissue thiol levels of HGGs were found to be higher than the control group $(p=0.001)$. Although the median thiol levels of Grade 4 gliomas were higher than those of Grade 3, no statistically significant difference was noted ( $p=0.076)$. When all tumors were compared according to the IDH1 mutation presence, IDH1-negative (IDH1-) HGGs had higher thiol contents than IDH1 mutant (IDH1+) HGGs ( $\mathrm{p}=0.001)$. The thiol levels of Grade 4 IDH1- gliomas were statistically significantly higher than of Grade 3 gliomas $(p=0.023)$, but no statistically significant difference between the thiol levels of Grade 3 and Grade 4 IDH1+ tumors was noted $(\mathrm{p}=0.459)$.

CONCLUSION: We have demonstrated the higher thiol concentrations of HGGs, particularly IDH1- ones. The sulfhydryl contents of gliomas as an indicator of tumoral antioxidant capacity may be responsible for the treatment resistance of IDH1- gliomas, the mechanism of which is not clear. Thiols can be a novel target for treatment, considering the unsatisfactory results of current modalities for HGGs.

KEYWORDS: High-grade glioma, Glioblastoma, IDH1, Thiol, Antioxidant

ABBREVIATIONS: COX-2: Cyclooxygenase-2, GBM: Glioblastoma, GILT: Gamma-interferon-inducible lysosomal thiol reductase, GSH: Glutathione, HGG: High-grade glioma, IDH1: Isocitrate dehydrogenase 1, IDH1+: IDH1 mutant, IDH1-: IDH1 negative, IKK: IKB kinase, MRI: Magnetic resonance imaging, NADPH: Nicotine adenine disphosphonucleotide, NCSS: Number Cruncher Statistical System, NFкB: Nuclear factor kappa B, ROC: Receiver operating characteristic, Ros: Reactive oxygen species, SH: Sulfhydryl, TAC: Total antioxidant capacity, WHO: World Health Organization

Sevket EVRAN (D) : 0000-0003-1041-252X

Ahmet KAYHAN (D) : 0000-0001-6549-8303

Oguz BARAN (D) : 0000-0002-2345-4318

Serdar CEVIK (D) : 0000-0002-2733-4233
Salim KATAR (D) : 0000-0002-8311-1122

Mustafa KAYA (D) : 0000-0001-9401-0311

Derya SONMEZ (D) : 0000-0001-8514-0704
Huriye SERIN

(iD) : 0000-0002-0436-7657

Hakan HANIMOGLU (iD) : 0000-0002-8830-9525

Mehmet Yasar KAYNAR (D) : 0000-0001-7327-836X 


\section{INTRODUCTION}

$\mathrm{H}$ igh-grade gliomas (HGG) comprise the World Health Organization (WHO) Grade 3 and Grade 4 gliomas, which are seen predominantly in 50-60-year-old men (32). Grade 4 glioma, which is also called "glioblastoma (GBM)," is the most common primary malignant brain tumor in adults and, despite the new treatment options, has poor prognosis, with a median survival ranging between 12 and 15 months (1). GBM can be divided into primary and secondary, which arises de novo and transforms from a lower grade glioma, respectively (31).

Isocitrate dehidrogenase 1 (IDH1) enzyme, which belongs to the Krebs cycle, catalyzes the reversible oxidation of isocitrate to procure a-ketoglutarate and nicotine adenine disphosphonucleotide (NADPH) (10). NADPH inhibits intracellular oxidative damage (22). IDH1 mutations were first described for GBMs in 2008 (25), which were found to be related with better prognosis and longer survival in the whole spectrum of gliomas (15). While the mutation of IDH1 occurs rarely in primary GBM, it has been reported in up to $85 \%$ in secondary GBM, which has better prognosis than primary GBM (40).

Thiols, also known as "mercaptans," are compounds that contain a functional sulfhydryl (-SH) group, which comprises a hydrogen atom and a sulfur atom (35). Since the sulfhydryl group acts as a major target for oxidant compounds, thiols are responsible in neutralizing oxidative stress by forming disulfide (-SS) bonds. Although thiols take a part in signal transduction, metabolism, proliferation, and cell death processes (2), they are the main determinant factors in assessing the total antioxidant capacity (TAC) of cellular homogenates with their antioxidant functions (3). Measurement of tumor's antioxidant capacity and modifications of sulfhydryl group have become a current issue for cancer treatment $(5,12)$.

Chemotherapy and radiotherapy, which are the treatment options for HGGs, can be used to induce the overproduction of reactive oxygen species (ROS), which cause oxidative stress and apoptosis of tumor cells (41). Thus, the cancer cells can produce more antioxidants to gain resistance against chemotheraphy or radiotherapy (29). Limiting the cellular antioxidant defense system of tumors reduces their neutralizing ability of oxidative damage, which makes them vulnerable to oxidative stress, resulting in tumor cell death. In this respect, investigating the compounds, which cause a higher antioxidant capacity of tumors, can be useful for increasing the effectiveness of treatment and finding better treatment options for incurable tumors especially GBMs.

In this study, we investigated the concentration of thiols, which are the main antioxidant compounds of intracellular milieu, and its distribution in different HGG grades. Also, we researched whether any association exists between tumor's cellular thiol content and IDH1 mutation, which is a prognostic factor for gliomas.

\section{MATERIAL and METHODS}

This prospective study was performed in collaboration with
Haseki Training and Research Hospital's Neurosurgery Clinic and Istanbul Training and Research Hospital's Biochemistry Department. Patients with a histopathologic diagnosis of HGG, consisting of the WHO Grade 3 or Grade 4, were included in the study. They, along with their relatives, were informed in detail, and those that signed the informed consent were included. Ethics committee approval was obtained from the local ethics committee, and our study was planned in accordance with the Declaration of Helsinki.

\section{Patient Population}

A total of 41 patients who had their first surgery due to HGG between the years 2017 and 2019 were included. Patients who had recurrent surgery were excluded from the study to eliminate oxidant effects of radio- and chemotherapy on tissues. Patients who had any other neoplastic diseases, signs of infection, and recent major surgery history and did not want to contribute to the study were excluded from the study. All participants were evaluated in our clinical preoperative case meetings. Contrasted brain magnetic resonance imaging (MRI), routine blood workup, and other needed specialty consultations were done. All patients and their relatives were informed about the benefits and risks of surgery preoperatively and signed the informed consent form. All operated patients were followed up at regular intervals after surgery. Pathology reports were assessed to confirm HGG diagnosis and note the IDH1 mutation presence. IDH1 mutated and nonmutated tumors were referred as IDH1 mutant (IDH1+) and IDH1negative (IDH1-), respectively.

\section{Control Samples}

The control samples were obtained from people autopsy series in the Department of Forensic Medicine. Poisoning and the cases with any neoplastic, inflammatory, or other chronic diseases, which were detected during autopsy, were excluded from the study. Also, the specimens with a sign of any kind of brain lesions were excluded from the study. The control group consisted of 21 people, 11 of whom died in traffic accidents, 6 by falling from height, and 4 by shot gun assault.

\section{Specimen Handling}

Glioma samples were procured from patients during surgery. Attention was paid for taking samples from the most viable parts of tumors, avoiding necrotic and cystic parts, which were confirmed with preoperative radiological investigations. The samples were divided into two same-sized portions. The first portions of these samples were fixed in $10 \%$ formalin for pathological investigations, and the others were frozen at $-80^{\circ} \mathrm{C}$ for biochemical analyses. Healthy glial tissues were extracted from the control group during autopsies, which were performed within the first 4 hours of death. All of the obtained samples taken from control group were stored at $-80^{\circ} \mathrm{C}$ for upcoming biochemical analyses.

\section{Sample Preparation}

Tissue samples were thawed at room temperature, which have been preserved at $-80^{\circ} \mathrm{C}$ previously. They had been weighed on a precision scale and phosphate tamponade (PBS, $0.1 \mathrm{M}$, $\mathrm{pH}=7.4$ ) added with $1: 9$ ratio. Samples were homogenized 
using MICCRA, Germany homogenisator. Samples were kept in ice to avoid heat that cause protein loss. After centrifugation at $5,000 \mathrm{rpm}$ for 5 minutes, supernatants were divided into equal portions for two different runs.

\section{Biochemical Analysis}

Protein and thiol measurements had been performed in these supernatants. Protein levels were evaluated as pair by a commercially available biochemistry auto-analizator (Beckman Coulter, AU5800, USA) with calorimetric method. Thiol levels were measured using the thiol quantification kit (Innova Biosciences, Catalog No: 418-0002). All measurements have been applied upon the manufacturer's request. All samples have been worked as a pair. Thiol concentration was measured per $\mathrm{mg}$ protein to eliminate errors caused by protein loss. The detecting range of thiol kit was $5-250 \mu \mathrm{M}$.

\section{Immunohistochemical Analyses}

4-micrometer-thick (4 micron) sections of formalin-fixed paraffin embedded tissues were placed on 3-aminopropyletxylene-covered slides. Subsequently, they were stained with rabbit polyclonal Dianova IDH1 R132H antibody (1/20 titer; H09 clone, mouse monoclonal antibody) following the manufacturer's protocol. Briefly, staining was performed on the Ventana Bench Mark Ultra (Ventana Medical Systems Inc.).

The staining protocol included cell conditioning 1 for 60 minutes, pre-peroxydase inhibition, and primary antibody incubation for 40 minutes at $37^{\circ} \mathrm{C}$, applying the amplification kit (Ventana Medical Systems Inc.) for 4 minutes at $37^{\circ} \mathrm{C}$ to increase the signal intensity. UltraView Universal DAB Detection Kit (Ventana Medical Systems Inc.) was used to detect Isocytrate dehydrogenase 1 (IDH1) protein expression. Tissues were counterstained with hematoxylin for 16 minutes and bluing reagent for 4 minutes.

\section{Statistical Analyses}

The Number Cruncher Statistical System (NCSS) 2007 (Kaysville, Utah, USA) program was used for statistical analyses. Definitive statistical methods (mean, standard deviation, median, first quartile, third quartile, frequency, minimum, maximum) were used to assess the study data. Comparing the quantitative variables that did not show normal distribution between the two groups was achieved by the Mann-Whitney $U$ test. Receiver operating characteristic (ROC) analysis was used to determine the cutoff. $P<0.05$ was considered statistically significant.

\section{— RESULTS}

This study consists of mainly two groups: HGGs and controls. The HGG group was divided into subgroups according to their grades and IDH1 mutation existence to investigate the relation between thiol levels, grades, and IDH1 mutations.

The HGG group included 14 (34.1\%) women and 27 (65.9\%) men, with a mean age of $46.73 \pm 10.6$ years (range, 27 to 67 years). The control group had 8 women and 13 men, with a mean age of $44.42 \pm 12.02$ years (range, 21 to 73 years).
The HGG group was separated into two subgroups according to the WHO grades of tumors. Grade $3 \mathrm{HGG}$ group consisted of 18 patients, with a mean age of $40.27 \pm 17.7$ years (range, 27 to 54 years), 6 (33.3\%) of whom were women and 12 (66.7\%) men. The most common symptom was headache $(47.7 \%)$, followed by seizure (33.3\%) and weakness (19.0\%). Most of the Grade 3 gliomas were located at the right hemisphere (77.8\%) and frontal lobe (55.5\%).

In the Grade 4 HGG group, there were 23 patients, with a mean age of $51.78 \pm 7.1$ years (range, 41 to 67 years), $8(34.8 \%$ ) of whom were women and 15 (65.2\%) men. The most common finding of Grade 4 glioma was headache (48.3\%), followed by weakness $(17.3 \%)$, seizure $(17.3 \%)$, vertigo $(10.3 \%)$, visual problems (3.4\%), and loss of consciousness (3.4\%). While most of the Grade 4 gliomas were located at right hemisphere (78.2\%), the temporal lobe had a slightly higher incidence from the other lobes for tumor presence. Table I summarizes the detailed clinical characteristics of the HGG group.

IDH1 mutation was found to be positive in 8 (44.5\%) of 18 Grade 3 glioma and 11 (47.8) of 23 Grade 4 glioma patients. A total of 19 patients $(46.3 \%)$ had IDH1 mutation, whereas 22 $(53.7 \%)$ did not.

Median tissue thiol levels of HGG and control groups were 0.18 $(0.09,0.27)$ and $0.07(0.06,0.08)$, respectively. Higher median thiol level of patient group than control group was found to be statistically significant $(p=0.001)$ (Table II) (Figure 1).

Thiol levels of HGG group were investigated separately according to the grades. While the median level of Grade 3 tumors was $0.16(0.09,0.23)$, Grade 4 tumors was $0.25(0.11$, 0.31). Although the individual tissue levels of both Grade 3 and Grade 4 tumor groups were higher than the control group with statistical significance $(p=0.001)$, a higher median thiol level of the Grade 4 group than the Grade 3 group was not statistically significant $(p=0.076)$ (Table III) (Figure 2).

Tissue thiol levels were analyzed regardless of the Grade of the tumor according to the IDH1 mutation presence. The median tissue level of IDH1+ tumors was $0.09(0.07-0.13)$, while that of the IDH1- tumors was $0.25(0.18-0.31)$, with a statistically significant difference between the two groups $(p=0.001)$ (Table IV) (Figure 3).

Both Grade 3 and Grade 4 HGG groups were divided into two subgroups to investigate the association between IDH1 mutation and tissue thiol levels. In the Grade 3 HGG group, median tissue thiol levels of IDH1+ and IDH1- subgroups were $0.09(0.07,0.11)$ and $0.22(0.17,0.26)$, respectively $(p=0.001)$. Also, the median tissue levels were $0.11(0.06,0.25)$ for IDH1+ and $0.30(0.24,037)$ for IDH1- subgroups in the Grade 4 HGG group. The higher levels of IDH1- subgroups than the IDH1+ subgroups were found to be statistically significant in both Grade 3 and Grade 4 HGG groups ( $p=0.001$ for Grade 3, $p=0.002$ for Grade 4).

The tissue thiol concentrations of both IDH1- and IDH1+ tumors were compared according to the grade of tumor. The difference between median levels of Grade 3 and Grade 4 IDH1+ tumors was not statistically significant $(p=0.459)$. In 
Table I: Clinical Characteristics of the High-Grade Glioma Patients

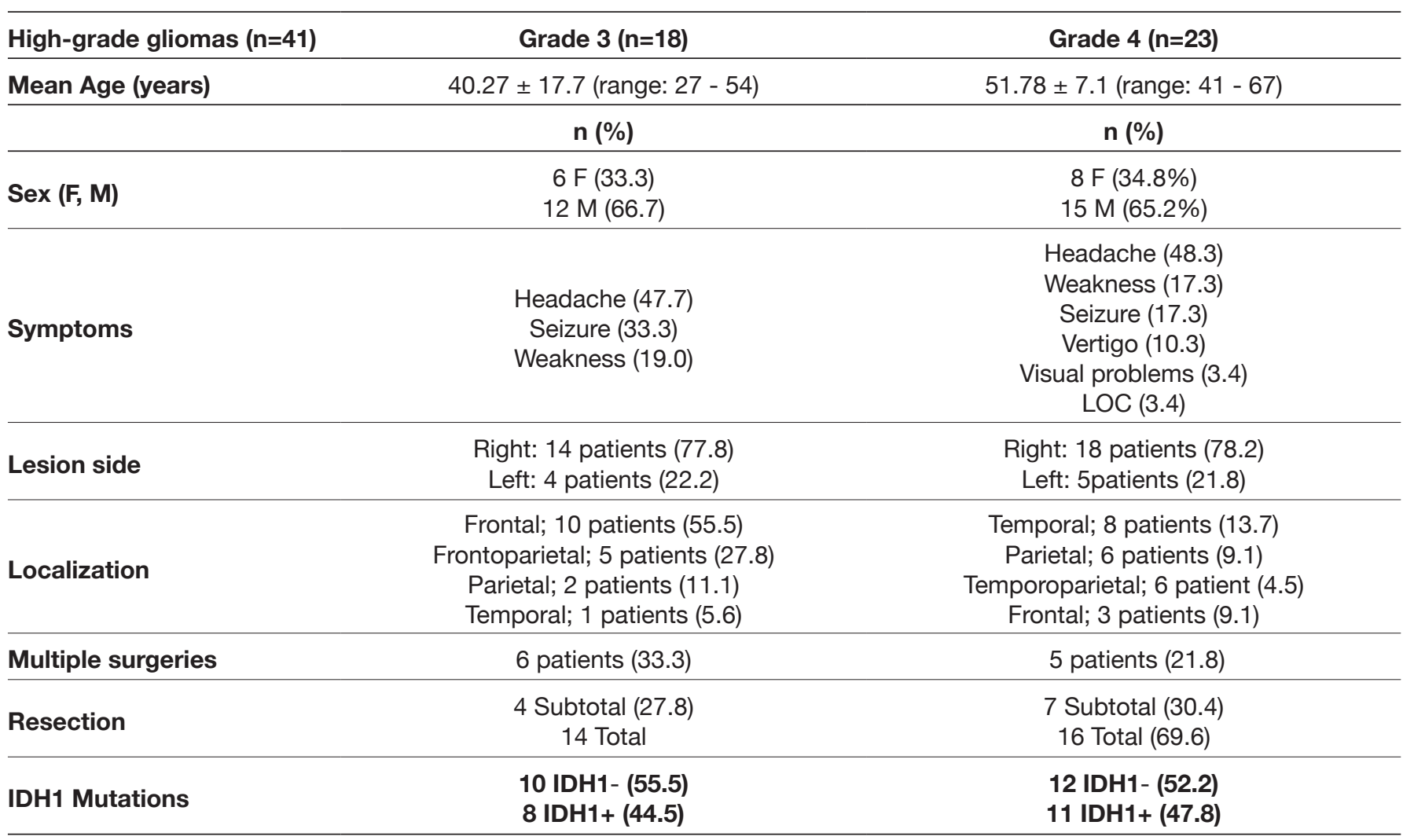

IDH1+: Isocitrate dehydrogenase 1 mutant, IDH1-: Isocitrate dehydrogenase 1 negative, LOC: Loss of consciousness.

Table II: Tissue Thiol Concentrations of Control and Patient Groups

\begin{tabular}{lcc}
\hline & Thiol & \\
\cline { 2 - 3 } & Median $(\mathbf{Q 1}, \mathbf{Q 3})$ & $\mathbf{p}$ \\
\hline Control & $0.07(0.06,0.08)$ & $\mathbf{0 . 0 0 1}$ \\
\hline Patients & $0.18(0.09,0.27)$ & \\
\hline
\end{tabular}

Mann-Whitney U test. Q1: First quartile, Q3: Third quartile

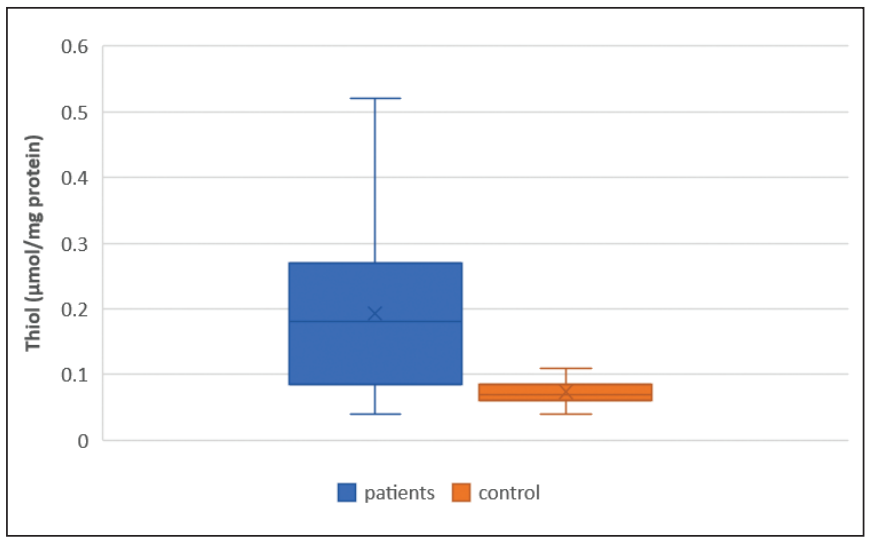

Figure 1: Distribution of tissue thiol concentrations in patient and control groups.
Table III: Tissue Thiol Concentrations of Grade 3, Grade 4 Gliomas and Control Groups

\begin{tabular}{lc}
\hline & Thiol \\
\cline { 2 - 2 } & Median $(\mathbf{Q 1}, \mathbf{Q 3 )}$ \\
\hline Control & $0.07(0.06,0.08)$ \\
\hline Grade 3 & $0.16(0.09,0.23)$ \\
\hline Grade 4 & $0.25(0.11,0.31)$ \\
\hline p (Grade 3 vs Control) & $\mathbf{0 . 0 0 1}$ \\
\hline p (Grade 4 vs Control) & $\mathbf{0 . 0 0 1}$ \\
p (Grade 3 vs Grade 4) & 0.076 \\
\hline
\end{tabular}

Mann-Whitney U test. Q1: First quartile, Q3: Third quartile.

contrast, IDH1- Grade 4 tumors had higher thiol levels, with statistically significance, than IDH1- Grade 3 tumors $(p=0.023)$ (Table V) (Figure 4).

ROC analysis was performed to determine the cutoff of thiol value in differentiating glioma and control groups. The area under the curve obtained from the evaluation was found to be 0.821 [AuROC ( $95 \% \mathrm{Cl}): 0.821$ (0.718, 0.923), $p=0.001$ ], while the thiol value was $\geq 0.12$, sensitivity $65.85 \%$, specificity 100\%, PPV 100, and NPV 60 (Figure 5). 
ROC analysis was performed to determine the cutoff of thiol value to differentiate IDH1 + and IDH1- groups. The area under the curve obtained from the evaluation was found to be 0.893 [AuROC (95\% Cl): $0.893(0.788,0.998), p=0.001]$. For the case where the thiol value was $\geq 0.14$, the sensitivity was found to be 100\%, specificity 78.9, PPV 84.6, and NPV 100 (Figure 6).

\section{DISCUSSION}

Thiols are one of the most important antioxidant molecules for living organisms. While their antioxidant effects prevent

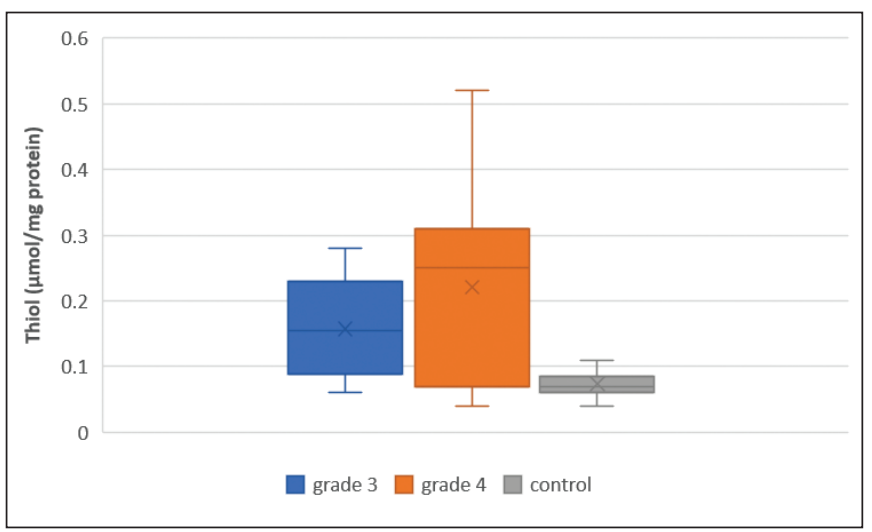

Figure 2: Distribution of tissue thiol concentrations in Grade 3 and Grade 4 glioma and control groups.

Table IV: Comparison of Tissue Thiol Concentrations According to IDH1 Mutation Presence

\begin{tabular}{lcc}
\hline & Thiol & \\
\cline { 2 - 3 } & Median $(\mathbf{Q 1}, \mathbf{Q 3})$ & $\mathbf{p}$ \\
\hline IDH1+ & $0.09(0.07,0.13)$ & $\mathbf{0 . 0 0 1}$ \\
\hline IDH1- & $0.25(0.18,0.31)$ & \\
\hline
\end{tabular}

IDH1+: Isocitrate dehydrogenase 1 mutant, IDH1-: Isocitrate dehydrogenase 1 negative. Mann-Whitney $U$ test. Q1: First quartile, Q3: Third quartile. cancer in healthy organism, they also can facilitate the survival of tumoral tissue, forming chemo- or radioresistancy. At this point, thiols seemed to be a double-edged sword. Understanding the mechanism of their different behavior at different tumor types via possible different pathways may be beneficial for finding out new treatment strategies.

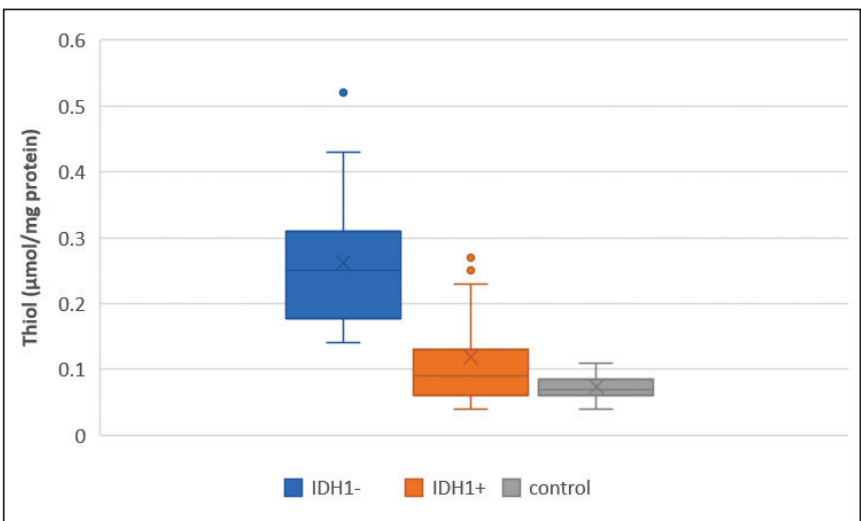

Figure 3: Distribution of tissue thiol concentrations in IDH1 mutant (IDH1+), IDH1-negative (IDH1-), and control groups.

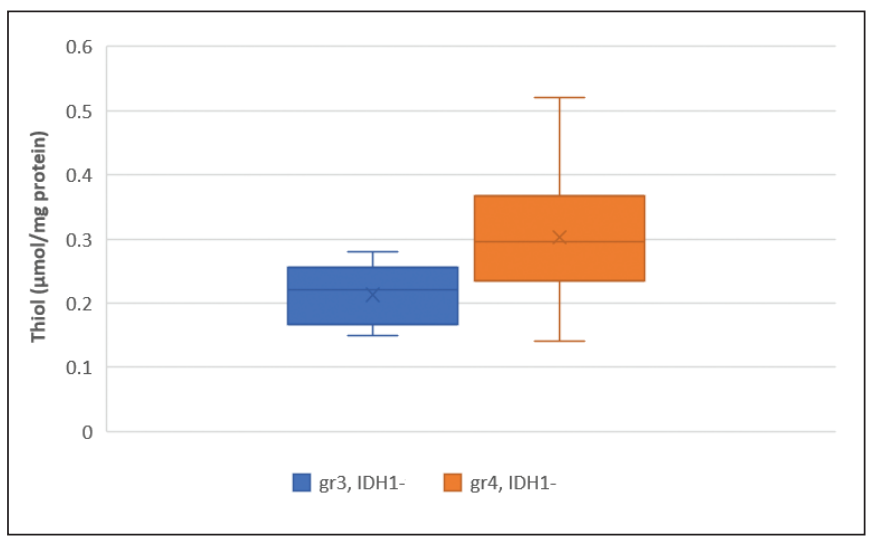

Figure 4: Distribution of tissue thiol concentrations in IDH1negative (IDH1-) tumors according to grades.

Table V: Tissue Thiol Concentration according to Grades and IDH1 Mutation Presence

\begin{tabular}{lccc}
\hline & & Thiol & \\
\hline \multirow{2}{*}{ Grade 3 } & & Median (Q1, Q3) & $\mathbf{p}$ \\
\hline \multirow{2}{*}{ Grade 4 } & $\mathrm{IDH} 1-$ & $0.22(0.17,0.26)$ & $\mathbf{0 . 0 0 1}$ \\
\cline { 2 - 4 } & $\mathrm{IDH} 1+$ & $0.09(0.07,0.11)$ & $\mathbf{0 . 0 0 2}$ \\
\cline { 2 - 4 } & $\mathrm{IDH} 1-$ & $0.30(0.24,0.37)$ & $\mathbf{0 . 0 2 3}$ \\
\hline & $\mathrm{IDH} 1+$ & $0.11(0.06,0.25)$ & 0.459 \\
\hline
\end{tabular}

IDH1+: Isocitrate dehydrogenase 1 mutant, IDH1-: Isocitrate dehydrogenase 1 negative. Mann-Whitney U test. Q1: First quartile, Q3: Third quartile. 


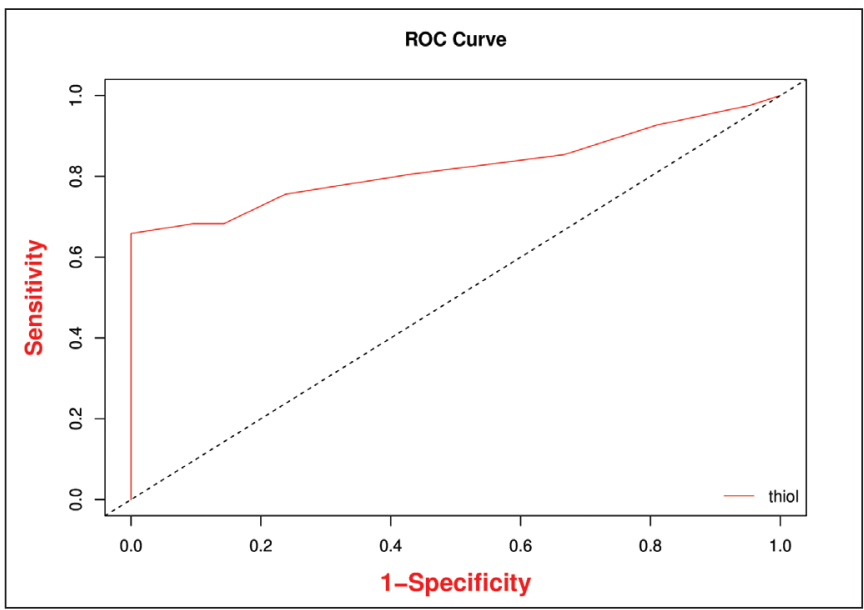

Figure 5: The ROC curve analysis of tissue thiol levels in glioma and control groups.

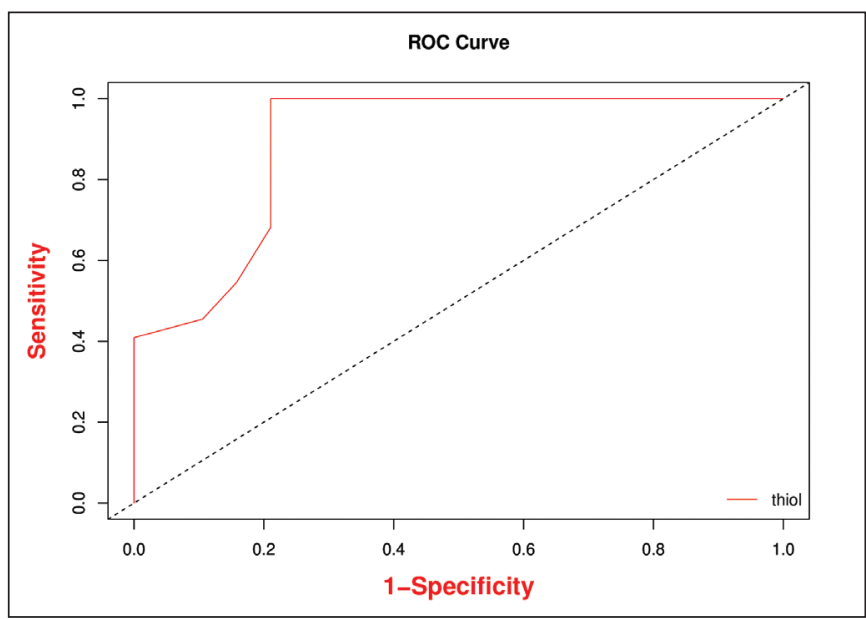

Figure 6: The ROC curve analysis of tissue thiol levels in IDH1 mutant (IDH1+) and IDH1 negative (IDH1-).

One of the immunoresponsive processes is related to an enzyme called as gamma-interferon-inducible lysosomal thiol reductase (GILT), which includes a sulfhydryl group and has a disulfide bond reduction function in the antigen presentation process $(16,26)$. While a lower expression of GILT was found to be connected to a worse prognosis of diffuse large B-cell lymphoma patients (34), it has a higher expression for melanoma patients as previously reported (30). Eventually, Chen et al. researched this subject in cell cultured glioma tissues (6). Additionally, they found the higher expression of GILT in glioma cell lines, silencing GILT, which resulted in the suppression of proliferation, colony formation, migration, and tumor growth and the induction of cell cycle arrest and apoptosis. Although we are congruent with them in our results, the other molecules containing sulfhydryl groups may be have a part in this neoplastic process, which is not certainly clarified.

Nuclear factor kappa B (NF-kB) was associated with cancer previously (4). Linnewiel-Hermoni et al. investigated the effect of carotenoid derivates on NF-KB and its mechanism in both cancer and bone cells (23). They reported that the carotenoid derivates inhibited NF-KB pathway by using specific thiol groups of p65 and IKB kinase (IKK), which are the two key proteins of this pathway. As a consequence, they suggested the carotenoid derivates contribute to the prevention of cancer. When the poor prognosis of HGGs and their higher tissue thiol concentration are considered, thiol-targeted therapy modalities can ensure a better prognosis. For this purpose, finding the molecules that are exceeding the blood brain barrier or are usable in the surgical procedures, which can be achieved by understanding the mechanism via further studies in HGGs, might be helpful.

Deorukhkar et al. investigated the effects of "zerumbone" which is a cyclic sesquiterpene derived from ginger plant (20), on colorectal cancer cell lines (8). Their in vitro study demonstrated that the zerumbone contributes to radiationinduced cell cycle arrest in G2/M phase and apoptosis. One of their gripping findings was maintaining of radiosensitization caused by the zerumbone achieved with depleted glutathione (GSH) levels but neither boosted the radiation-induced ROS generation nor generated ROS by itself. Our study discussed that the HGGs have higher thiol levels than healthy brain tissues. Molecules, which target the thiol groups of these tumors, can be one of the treatment options to increase survival and health quality.

Withaferin $A$ is a steroidal lactone maintained from a medicinal plant called Withania somnifera and has anticancer impacts on various cancer types, such as myeloid leukemia (24), or renal cancer (7). Although withaferin A-induced apoptosis have been previously reported for head and neck carcinoma cells (36), Park et al. investigated the underlying mechanisms in vitro (33). They reported that the withaferin A-mediated apoptosis is independent of ROS production and cyclooxygenase-2 (COX-2) expression, which are related to different cancer types, such as melanoma (27), and renal cancers (14), respectively. Most importantly, they indicated that the thiol oxidation is an important mechanism for withaferin A-induced apoptosis and withaferin $A$ may target cysteine residues of proteins, such as kinases and chaperons. In this current issue, the sulfhydryl groups, which have elevated levels in the HGGs from the normal brain tissues, also can be a target for novel molecules, which may be used in the HGG treatment. Further studies are also needed.

A high level of consumption of cruciferous vegetables, such as broccoli and cauliflower, reduces the risk of various cancer types previously reported (17). Anticancer effects of the cruciferous vegetables have been found to be related to their high glucosinolate content (9). Kim et al. investigated the effect of sulphoraphane, which is a glucosinolate precursor, on the ovarian cancer cells, indicating the anticancer effect of sulphoraphane decayed by thiol-reducing agents but not by the ROS-scavenging antioxidants (19). However, they did not explain the underlying mechanism, and they suggested further studies are needed for understanding these pathways. Similarly, in our study, higher levels of reduced thiol concentrations of glial tumors correlate with poor prognosis. At this point, higher concentrations of thiol levels especially in higher 
grade and IDH1- subgroups may be one of the reasons of poor prognosis. Modalities, which target tumor's thiol content, may be a treatment option.

Previous studies have suggested the IDH1 mutations were found to be related with better prognosis and prolonged survival in glioma patients with different grades $(21,37)$. IDH1 catalyzes the oxidative carboxylation of isocitrate to a-ketoglutarate, which is a reaction that produces NADPH $(28,42)$. Production of GSH from the oxidized form of glutathione (GSSG) is dependent to NADPH (18). Also, reduced levels of intracellular GSH, which is a thiol compound and the most abundant intracellular antioxidant, lead to increased ROS levels in cells, causing apoptosis resistance $(11,13)$. From this point, Shi et al. investigated the inhibitor effects on tumor growth of elevated ROS levels and the depletion of GSH caused by IDH1 mutation (39). They concluded the inhibitor cell growth effect of IDH1 mutation may be caused by GSH depletion and ROS generation. Although they investigated GSH, which is a thiol compound, they collected data from the cell culture, while our study was human tissue and tumor based. At this point, both of these studies require further studies to understand certain mechanism of IDH1 mutation-related prognosis, especially from the tumoral antioxidant aspect.

Also, Shi et al. designed an additional cell culture-based study, wherein they investigated the relation between IDH1 mutation and chemosensitivity in gliomas (38). They pointed out the higher chemosensitivity of IDH1 mutant cell lines were associated with NADPH, GSH depletion, and elevated ROS generation. Our findings are parallel to theirs because of the higher thiol concentrations of IDH1- tumors, which indicate higher tumoral antioxidant capacity, chemoresistency, and worse prognosis. As a result, alternative treatment modalities, with mechanisms such as binding active thiol groups, may be an option for the treatment of these poor prognosed tumors.

Our findings indicate that HGGs, particularly IDH1- gliomas, have higher thiol concentrations than normal brain tissues. In this respect, decaying their antioxidant defense may be an option for improving the management of HGGs, which cannot be cured with current treatment options. Further studies are necessary to discover detailed mechanisms of antioxidant systems and how to modify them.

This study had some limitations. First, not all of the patients who had surgery in our clinic wanted to participate in the study, resulting in the restriction of our patient population. Also, all of the patients who could be involved in this study had been diagnosed histologically with Grade 3 or Grade 4 glioma, and consequently, we could not investigate the thiol content of low-grade gliomas. Further studies, which comprise a larger patient group, can be planned for more certain data.

\section{CONCLUSION}

Thiols are the main antioxidant molecules of the intracellular area. However, their anti-oxidizing abilities have crucial roles for maintaining survival of healthy cells; they can contribute to resistance against treatment and cause worse prognosis in HGGs. Exploring the underlying mechanisms can be helpful in discovering new target selective treatment strategies based on the thiol group. In this respect, our study can provide beneficial knowledge for further studies.

\section{ACKNOWLEDGMENT}

Tissue samples here were reused for the extension of our previous work. Preparation for publication of this article is partly supported by Turkish Neurosurgical Society.

The authors would like to thank Enago (www.enago.com) for the English language review.

\section{REFERENCES}

1. Ashta A, Motalleb G, Ahmadi-Zeidabadi M: Evaluation of frequency magnetic field, static field, and Temozolomide on viability, free radical production and gene expression (p53) in the human glioblastoma cell line (A172). Electromagn Biol Med 39(4):298-309, 2020

2. Baba SP, Bhatnagar A: Role of thiols in oxidative stress. Curr Opin Toxicol 7:133-139, 2018

3. Balcerczyk A, Bartosz G: Thiols are main determinants of total antioxidant capacity of cellular homogenates. Free Radic Res 37:537-541, 2003

4. Baud V, Karin M: Is NF-kappaB a good target for cancer therapy? Hopes and pitfalls. Nat Rev Drug Discov 8:33-40, 2009

5. Cha J, Kim H, Hwang NS, Kim P: Mild reduction of the cancer cell surface as an anti-invasion treatment. ACS Appl Mater Interfaces 10:35676-35680, 2018

6. Chen S, Wang Q, Shao X, Di G, Dai Y, Jiang X, Cheng L: Lentivirus mediated $Y$-interferon-inducible lysosomal thiol reductase (GILT) knockdown suppresses human glioma U373MG cell proliferation. Biochem Biophys Res Commun 509:182-187, 2019

7. Choi MJ, Park EJ, Min KJ, Park JW, Kwon TK: Endoplasmic reticulum stress mediates withaferin A-induced apoptosis in human renal carcinoma cells. Toxicol. In Vitro 25:692-698, 2011

8. Deorukhkar A, Ahuja N, Mercado AL, Diagaradjane P, Raju U, Patel N, Mohindra P, Diep N, Guha S, Krishnan S: Zerumbone increases oxidative stress in a thiol-dependent ROSindependent manner to increase DNA damage and sensitize colorectal cancer cells to radiation. Cancer Med 4:278-292, 2015

9. Fahey JW, Zalcmann AT, Talalay P: The chemical diversity and distribution of glucosinolates and isothiocyanates among plants. Phytochemistry 56:5-51, 2001

10. Georgescu MM, Kirsch KH, Akagi T, Shishido T, Hanafusa $\mathrm{H}$ : The tumor-suppressor activity of PTEN is regulated by its carboxyl-terminal region. Proc Natl Acad Sci U S A 96:1018210187, 1999

11. Gottesman MM, Fojo T, Bates SE: Multidrug resistance in cancer: Role of ATP-dependent transporters. Nat Rev Cancer 2:48-58, 2002

12. Greenwood HE, McCormick PN, Gendron T, Glaser M, Pereira R, Maddocks ODK, Sander K, Zhang T, Koglin N, Lythgoe MF, Årstad E, Hochhauser D, Witney TH: Measurement of tumor antioxidant capacity and prediction of chemotherapy resistance in preclinical models of ovarian cancer by positron emission tomography. Clin Cancer Res 25:2471-2482, 2019 
13. Guha P, Dey A, Sen R, Chatterjee M, Chattopadhyay S, Bandyopadhyay SK: Intracellular GSH depletion triggered mitochondrial Bax translocation to accomplish resveratrolinduced apoptosis in the U937 cell line. J Pharmacol Exp Ther 336:206-214, 2011

14. Hara S, Kondo Y, Matsuzawa I, Hashimoto Y, Kimura G, Akimoto M, Imura N: Expression of cycloxygenase-2 in human bladder and renal cell carcinoma. Adv Exp Med Biol 507:123126, 2002

15. Hartmann C, Hentschel B, Tatagiba M, Schramm J, Schnell O, Seidel C, Stein R, Reifenberger G, Pietsch T, von Deimling A, Loeffler M, Weller M: Molecular markers in low-grade gliomas: Predictive or prognostic? Clin Cancer Res 17:4588-4599, 2011

16. Hastings KT: GILT: Shaping the MHC class II-restricted peptidome and CD4(+) T cell-mediated immunity. Front Immunol 4:429, 2013

17. Higdon J V, Delage B, Williams DE, Dashwood RH: Cruciferous vegetables and human cancer risk: Epidemiologic evidence and mechanistic basis. Pharmacol Res 55:224-236, 2007

18. Izawa S, Maeda K, Miki T, Mano J, Inoue Y, Kimura A: Importance of glucose-6-phosphate dehydrogenase in the adaptive response to hydrogen peroxide in Saccharomyces cerevisiae. Biochem J 330 Pt 2:811-817, 1998

19. Kim SC, Choi B, Kwon Y: Thiol-reducing agents prevent sulforaphane-induced growth inhibition in ovarian cancer cells. Food Nutr Res 61(1):1368321, 2017

20. Kitayama T: Attractive reactivity of a natural product, zerumbone. Biosci Biotechnol Biochem 75:199-207, 2011

21. Kloosterhof NK, Bralten LBC, Dubbink HJ, French PJ, van den Bent $\mathrm{MJ}$ : Isocitrate dehydrogenase-1 mutations: A fundamentally new understanding of diffuse glioma? Lancet Oncol 12:83-91, 2011

22. Lee SM, Koh HJ, Park DC, Song BJ, Huh TL, Park JW: Cytosolic NADP(+)-dependent isocitrate dehydrogenase status modulates oxidative damage to cells. Free Radic Biol Med 32:1185-1196, 2002

23. Linnewiel-Hermoni K, Motro Y, Miller Y, Levy J, Sharoni Y: Carotenoid derivatives inhibit nuclear factor kappa B activity in bone and cancer cells by targeting key thiol groups. Free Radic Biol Med 75:105-120, 2014

24. Malik F, Kumar A, Bhushan S, Khan S, Bhatia A, Suri KA, Qazi GN, Singh J: Reactive oxygen species generation and mitochondrial dysfunction in the apoptotic cell death of human myeloid leukemia HL-60 cells by a dietary compound withaferin A with concomitant protection by $\mathrm{N}$-acetyl cysteine. Apoptosis 12:2115-2133, 2007

25. Mardis ER, Ding L, Dooling DJ, Larson DE, McLellan MD, Chen K, Koboldt DC, Fulton RS, Delehaunty KD, McGrath SD, Fulton LA, Locke DP, Magrini VJ, Abbott RM, Vickery TL, Reed JS, Robinson JS, Wylie T, Smith SM, Carmichael L, Eldred JM, Harris CC, Walker J, Peck JB, Du F, Dukes AF, Sanderson GE, Brummett AM, Clark E, McMichael JF, Meyer RJ, Schindler JK, Pohl CS, Wallis JW, Shi X, Lin L, Schmidt H, Tang Y, Haipek C, Wiechert ME, Ivy J V, Kalicki J, Elliott G, Ries RE, Payton JE, Westervelt P, Tomasson MH, Watson MA, Baty J, Heath S, Shannon WD, Nagarajan R, Link DC, Walter MJ, Graubert TA, DiPersio JF, Wilson RK, Ley TJ: Recurring mutations found by sequencing an acute myeloid leukemia genome. N Engl J Med 361:1058-1066, 2009
26. Maric M, Arunachalam B, Phan UT, Dong C, Garrett WS, Cannon KS, Alfonso C, Karlsson L, Flavell RA, Cresswell P: Defective antigen processing in GILT-free mice. Science 294: 1361-1365, 2001

27. Mayola E, Gallerne C, Esposti DD, Martel C, Pervaiz S, Larue L, Debuire B, Lemoine A, Brenner C, Lemaire C: Withaferin A induces apoptosis in human melanoma cells through generation of reactive oxygen species and down-regulation of Bcl-2. Apoptosis 16:1014-1027, 2011

28. Menon SG, Goswami PC: A redox cycle within the cell cycle: Ring in the old with the new. Oncogene 26:1101-1109, 2007

29. Narayanan D, Ma S, Özcelik D: Targeting the redox landscape in cancer therapy. Cancers (Basel) 12:1-29, 2020

30. Nguyen J, Bernert R, In K, Kang P, Sebastiao N, Hu C, Hastings $\mathrm{KT}$ : Gamma-interferon-inducible lysosomal thiol reductase is upregulated in human melanoma. Melanoma Res 26:125137,2016

31. Ohgaki H, Kleihues P: Genetic pathways to primary and secondary glioblastoma. Am J Pathol 170:1445-1453, 2007

32. Ostrom QT, Gittleman H, Truitt G, Boscia A, Kruchko C, Barnholtz-Sloan JS: CBTRUS statistical report: Primary brain and other central nervous system tumors diagnosed in the United States in 2011-2015. Neuro Oncol 20:iv1-iv86, 2018

33. Park JW, Min KJ, Kim DE, Kwon TK: Withaferin A induces apoptosis through the generation of thiol oxidation in human head and neck cancer cells. Int J Mol Med 35:247-252, 2015

34. Phipps-Yonas H, Cui H, Sebastiao N, Brunhoeber PS, Haddock E, Deymier MJ, Klapper W, Lybarger L, Roe DJ, Hastings KT: Low GILT expression is associated with poor patient survival in diffuse large b-cell lymphoma. Front Immunol 4:425, 2013

35. Prakash M, Shetty MS, Tilak P, Anwar N: Total thiols: Biomedical importance and their alteration in various disorders. Online $J$ Heal Allied Sci 8(2):1-9 2009

36. Samadi AK, Tong X, Mukerji R, Zhang H, Timmermann BN, Cohen MS: Withaferin A, a cytotoxic steroid from Vassobia breviflora, induces apoptosis in human head and neck squamous cell carcinoma. J Nat Prod 73:1476-1481, 2010

37. Sanson M, Marie Y, Paris S, Idbaih A, Laffaire J, Ducray F, El Hallani S, Boisselier B, Mokhtari K, Hoang-Xuan K, Delattre JY: Isocitrate dehydrogenase 1 codon 132 mutation is an important prognostic biomarker in gliomas. J Clin Oncol 27: 4150-4154, 2009

38. Shi J, Sun B, Shi W, Zuo H, Cui D, Ni L, Chen J: Decreasing GSH and increasing ROS in chemosensitivity gliomas with IDH1 mutation. Tumor Biol 36:655-662, 2015

39. Shi J, Zuo H, Ni L, Xia L, Zhao L, Gong M, Nie D, Gong P, Cui $\mathrm{D}$, Shi W, Chen J: An IDH1 mutation inhibits growth of glioma cells via GSH depletion and ROS generation. Neurol Sci 35: 839-845, 2014

40. Szopa W, Burley TA, Kramer-Marek G, Kaspera W: Diagnostic and therapeutic biomarkers in glioblastoma: Current status and future perspectives. Biomed Res Int 2017:8013575, 2017

41. Trachootham D, Alexandre J, Huang P: Targeting cancer cells by ROS-mediated mechanisms: A radical therapeutic approach? Nat Rev Drug Discov 8:579-591, 2009

42. Yan H, Parsons DW, Jin G, McLendon R, Rasheed BA, Yuan W, Kos I, Batinic-Haberle I, Jones S, Riggins GJ, Friedman H, Friedman A, Reardon D, Herndon J, Kinzler KW, Velculescu VE, Vogelstein B, Bigner DD: IDH1 and IDH2 mutations in gliomas. N Engl J Med 360:765-773, 2009 